several deficiencies are addressed. A few additional specialist facilities might be developed both in prisons and in hospitals to promote research and training. But it would be a brave psychiatrist outside the special hospitals who took on the responsibility for a specialist unit for psychopaths in the current climate. The Mental Health Act 1983 places responsibilities on psychiatrists that in many cases cannot be fulfilled. Psychiatrists and patients may be caught in a dilemma whereby no one wishes to take responsibility for an unacceptable risk.

If proposals such as increased use of transfer of psychopaths to hospital under section 47 of the Mental Health $\mathrm{Act}^{22}$ are to take place then the covert political pressures to continue to detain those who are dangerous after the expected dates of their release must be removed. An alternative to detention in hospital without time limit when no effective treatment can be given but the patient remains potentially dangerous will also have to be found for psychopaths, possibly by using determinate sentences for treatment as in the Netherlands. Most importantly, psychiatrists will need to inform other professionals, the media, and ultimately the public about what can realistically be achieved with treatment and that psychiatric hospitals are no longer places that can provide long term custodial care.

It is paradoxical that other professionals such as probation officers and members of the Parole Board accept that a proportion of their clients will reoffend and that these reoffenders do not risk widespread public opprobrium or reflex disciplinary measures. Psychiatrists in general, and forensic psychiatrists in particular, find themselves increasingly being expected to deliver the impossible $-100 \%$ safety, which no treatment in medicine can claim. They will therefore be obliged to practise increasingly defensively.

Unless the current problems of inadequate service provision, lack of research and training, irrelevant mental health legislation, and unrealistic public expectations of the power of psychiatry are addressed little progress will be made in improving the care of psychopaths and indeed many other potentially dangerous patients. Meanwhile, the disasters, inquiries, and suspensions will continue.

Senior Lecturer in Forensic Psychiatry,

Department of Psychological Medicine,

St Bartholomew's Hospital,

London EC1A 7BE

Consultant Forensic Psychiatrist,

North West Thames Forensic Psychiatry Service,

London W11 2PS

1 Hamilton J. Special hospitals and the state hospital. In: Bluglass R, Bowden P, eds. Principals and practice of forensic psychiatry. Edinburgh: Churchill Livingstone, 1990:1363-73.

2 Government Statistical Service. In-patients formally detained in hospitals under the Mental Health Act 1983 and other legislations, England, 1984-1988/9. Statistical Bulletin 1991;2:91.

Coid JW. Mentally abnormal offenders on remand. I. Rejected or accepted by the NHS? II. Comparison of services provided by Oxford and Wessex regions. BMF 1988;296;1779-84.

4 Police arrest man after Broadmoor escape. Independent 1991 July 23.

5 Broadmoor sex assault man escapes on day trip. Independent 1991 Oct 18

6 Psychopath killed girl after release. Independent 1991 Oct 3.

Psychopath killed girl after release. Independent 1991 Oct 3.
Psychiatrists to lead inquiry into killings. Independent 1991 Oct 4.

Psychiatrists to lead inquiry into killings. Independent 1991

8 Pilkington E. Fear on the streets. Guardian 1992 Feb 5:19.

Coid JW. DSM-III diagnosis in criminal psychopaths; a way forward. Criminal Behaviour and Mental Health (in press)

11 Strasburger L. The treatment of antisocial syndromes: the therapist's feelings. In: Reid W, Dorr D, Walker J, Bonner J, eds. Unmasking the psychopath. New York: Norton, 1986: 191-207.

12 Symington N. The response aroused by the psychopath. International Review of Psychoanalysis 1980;7:291-8

13 Scottish Home and Health Department. Repont of a public local inquiry into circumstances surrounding the escape of two patients on 30th November 1976 and into security and other arrangements at the hospital. Edinburgh: HMSO, 1977.

14 Norris M. Integration of special hospital patients into the community. Aldershot: Gower, 1984

15 Bailey J, MacCulloch MJ. Patterns of reconviction in patients discharged directly to the community from a special hospital: implications for aftercare. Fournal of Forensic Psychiatry (in press).

16 Rice ME, Quinsey VC, Harris GT. Sexual recidivism among child molesters released from a maximum security institution. F Consult Clin Psychol 1991;3:381-6.

17 Copas JB, Whitely JS. Predicting success in the treatment of psychopaths. Br $\mathcal{F}$ Psychiatry 1976:129:388-92.

18 Grounds AT, Quayle MT, France J, Brett T, Cox M, Hamilton JR. A unit for "psychopathic disorder" patients in Broadmoor hospital. Med Sci Law 1987;27:21-31.

19 Department of Health, Home Office. Review of health and social services for mentally disordered offenders and others requiring similar services. London: Department of Health, Home Office, 1991. 20 Home Office, Department of Health and Social Security. Report of the committee on mentally abnormal offenders. London: HMSO, 1975. (Butler report; Cmnd 6244.)

21 Chiswick D. What mentally ill offenders need. BMJ 1992;304:267-8.

22 Mawson D. Psychopaths in special hospitals. Bulletin of the Royal College of Psychiatrists 1983;7:178-81.

\title{
The future of primary health care
}

\section{From the margins to the mainstream}

National initiatives to develop primary care and increase its influence on secondary care have proliferated recently..$^{1-3}$ Together with a series of influential policy discussion documents $^{4-7}$ these aim at profound and interrelated changes in the content, emphasis, and organisation of primary care. The transfer of strategic management responsibility for primary care from the Department of Health to regional health authorities just over a year ago was part of this.

By necessity, regional health authorities started tackling the most urgent topics first, which included fundholding and learning the business of family health services authorities. Responsible for both family health services authorities and district health authorities, regions also have a wider role in ensuring effective joint purchasing of primary and secondary care and the provision of an integrated service. North East Thames's Primary Health Care in the 1990s-A Strategic Statement is a positive first step. ${ }^{6}$ A clear statement of the regional health authorities' commitment to primary care, it will help to develop a shared understanding of needs and priorities. It establishes the essential interdependence of primary and secondary care and through wide consultation will already have started some of the difficult discussions about issues such as quality and resources.
The strategy identifies opportunities to develop a more effective system of primary care. Primary care must be seen as a core part of an improved health service, not just as a gateway to another part of the service. North East Thames will spend at least $£ 2 \cdot 1$ billion on primary care over the next five years.

The strategy emphasises health promotion and prevention among patients and working towards goals with measurable outcomes. Rising expectations among patients and the need for a better dialogue between users and service providers are recognised. The report refers to the changing range of services available in primary care and the increasing focus on day case surgery in hospitals.

Changes in national policy have meant that general practitioners and family health services authorities have made considerable progress in changing patterns of service. The strategy, however, emphasises the need for both sustained investment of resources and targeting attention at deprived areas of the "outer city" which have so far been neglected. It concludes by identifying the need for developing professional education and training and promoting innovation, good practice, and more flexible budgeting.

Although it has strengths, the strategy is not without its problems. Firstly, it predicts an exponential pace for practice 
development, with little time for consolidation or review. It assumes a level of energy, commitment, and skills that will take time to become the norm rather than the exception. Smaller practices will undoubtedly face difficulties, and, with nearly half of North East Thames's general practitioners in singlehanded practice, it may take more than "greater understanding and closer networks between smaller practices" to aid their development.

Secondly, strategic emphasis on health promotion and prevention may be appropriate, but so is greater recognition that a large part of general practitioners' work is appropriately associated with diagnosing and treating chronic and minor illness.

Thirdly, there is the problem of primary care in inner London. As the report suggests, Acheson identified many of these and suggested good solutions. ${ }^{8}$ More than 10 years on, however, there remain specific obstacles, such as the high cost of improving premises and finding suitable sites. The report does not discuss the potentially deleterious effect of weighted capitation in inner London. The legacy of low investment in primary care in London cannot be ignored. Although avoiding a problem that seems intractable is understandable, the opportunity to call the other Thames regions for a joint approach should not be missed.

Finally, a strategy aiming at improving effectiveness must consider who does what in primary care. Wider changes, such as the rapid increase in the use of practice nurses and the potential for an expanded role for nurse practitioners, suggest the need to consider the role of nurses. Improvements over the next five years will rely as much on effective joint working between professional groups as it will on the integration of district health authorities and family health services authorities, yet this is relatively unexplored.

Wittingly or otherwise primary care is becoming a partner in the mainstream rather than the margins of the health service. The North East Thames strategy is a welcome statement of the potential for primary care in developing health care in the 1990s.

VIRGINIA MORLEY

Project Officer,

Primary Care Development,

North West Thames Regional Health Authority,

London W2 3QR

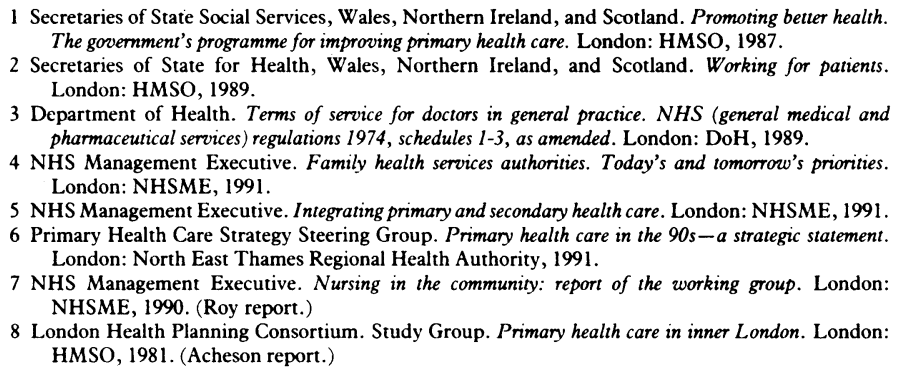

Over the past few years listeriosis has changed from being an obscure disorder to a topic of general concern. The belief that the main source of the infection is food emerged during the late 1980 s, but in fact this was first suggested only a year after the first description of the disease in $1927 .^{1}$ Listeria monocytogenes may also, however, be transmitted by direct contact with infected animals (causing local rather than systemic disease) and it may spread between neonates shortly after delivery, though both of these routes are uncommon.

Methods of isolating $L$ monocytogenes have greatly improved since the mid-1980s and the new tests have shown that it is widespread in the environment, including in many sorts of foods. ${ }^{2}$ A series of outbreaks of food poisoning of "a common source" type occurred in North America and Europe in the 1980s, some of which affected more than 100 people. These brought about the general interest in foodborne listeriosis. Single sporadic cases of foodborne listeriosis also occur. Dairy produce, meat, fish, and vegetable foods have all been associated with transmission of the infection. ${ }^{2}$ Although varied in their constituents, these foods had in common the features of being highly processed, having extended shelf lives, and being capable of supporting the multiplication of $L$ monocytogenes.

The incubation period between ingestion of contaminated food and the onset of symptoms may vary from one day to more than three months, which helps explain why in most cases of listeriosis the source of infection is not identified. In those few cases in which a food has been identified as the vehicle of infection the implicated strain of $L$ monocytogenes has been at high concentrations $\left(>10^{3} / \mathrm{g}\right.$ of food). Since, however, it is often difficult or impossible to obtain the food consumed by patients with listeriosis these data do not exclude the possibility of a lower dose being infective.

One of the puzzling features of listeriosis is that although the organism is widely distributed in the environment (including food), the overall rate of infection is low. The reasons for this are obscure, as are the factors that lead to large outbreaks - though there is some evidence for variations in virulence among strains of $L$ monocytogenes. Case-control studies of apparently sporadic cases have been carried out in several countries (including the United States and England and Wales), and as more of these are completed fresh evidence is likely to emerge to implicate specific foods as well as any other risk factors.

The food industry has been active in investigating listeria in foods and the factory environment, in implementing hazard analysis, and in establishing codes of practice. The ideal goal should be the total exclusion of listeria from processed foods, and thus should be pursued vigorously-but it is probably unattainable. The responses by national and international regulatory authorities to the presence of $L$ monocytogenes in certain foods on retail sale have varied from a total exclusion of such foods to a tolerance of some contamination (as is the policy in Britain).

Unlike most other foodborne pathogens $L$ monocytogenes can multiply (albeit slowly) at refrigeration temperatures. Hence not only is it important to try to exclude the organism from food, it is also important for efforts to be made to inhibit its multiplication and survival. This problem was addressed with the introduction in 1990 of the Food Safety Act with respect to temperature control. ${ }^{7}$ Nevertheless, the recommendations issued for the shelf lives of certain types of foods 